\title{
Teachers' Knowledge and Issues in the Implementation of School-Based Assessment: A Case of Schools in Terengganu
}

\author{
Gopala Krishnan Sekharan Nair ${ }^{1}$, Roszainora Setia ${ }^{1}$, Nor Zaitolakma Abdul Samad ${ }^{1}$, Raja Nurul Huda Binti Raja \\ Zahri $^{2}$, Azyanee Luqman ${ }^{3}$, Thenmolli Vadeveloo ${ }^{4} \&$ Haslina Che $\mathrm{Ngah}^{5}$ \\ ${ }^{1}$ Academy of Language Studies, Universiti Teknologi MARA (UiTM) Dungun, Terengganu, Malaysia \\ ${ }^{2}$ Sultan Omar Secondary School, Dungun, Malaysia \\ ${ }^{3}$ Faculty of Business Management, Universiti Teknologi MARA, Dungun, Terengganu, Malaysia \\ ${ }^{4}$ Faculty of Administrative Science \& Policy Studies, Universiti Teknologi MARA, Dungun, Terengganu, \\ Malaysia \\ ${ }^{5}$ Faculty of Hotel \& Tourism Management, Universiti Teknologi MARA (UiTM) Dungun, Terengganu, Malaysia \\ Correspondence: Gopala Krishnan Sekharan Nair, Academy of Language Studies, Universiti Teknologi MARA \\ (UiTM) Dungun Campus, 23000 Dungun, Terengganu, Malaysia. E-mail: gopala@tganu.uitm.edu.my
}

Received: July 24, 2013 Accepted: December 11, 2013 Online Published: January 27, 2014

doi:10.5539/ass.v10n3p186 URL: http://dx.doi.org/10.5539/ass.v10n3p186

\begin{abstract}
In tandem with educational best practices the world over, School-based assessments (SBAs) were introduced in Malaysia in 2012 for secondary one students. This study investigated quantitatively and qualitatively matters such as the teachers' knowledge of SBAs and the issues faced when implementing SBAs. Whereas the factors contributing to the problems of SBA implementation was investigated only qualitatively. A sample of 60 English teachers in the district of Dungun, Terengganu, who were involved in SBAs from the beginning was used, out of this, 20 teachers were interviewed to obtain qualitative findings. It was found that teachers had satisfactory knowledge of planning an SBA tailored lesson. They also showed satisfactory knowledge of developing SBAs but appeared to have difficulty in the psychometrics of test analysis. As for issues faced by teachers, they were not indifferent to SBA implementation but team work and collaboration among SBA teachers needs to be improved. Teachers faced problems in SBA implementation but overall had a positive attitude towards SBA. Teachers voiced concerns over the lack of adequate staff numbers, lack of uniformity and a possible element of biasness in grading. Teachers also faced time constraints, lack of effective materials and methodologies and poor ICT facilities in schools. They also feared cheating by students in SBAs. Future researchers should investigate the success of SBA implementation after a few years.
\end{abstract}

Keywords: school-based assessments (SBAs), teachers' knowledge of SBAs, issues of implementing SBAs, knowledge of planning an SBA

\section{Introduction}

This paper reports on teachers' knowledge of School Based Assessment (SBA) for English Language teaching and learning in Terengganu, Malaysia. The paper looks into issues faced by the teachers in the implementation of School Based Assessment, and attempts to identify factors contributing to the problems in SBA implementation.

Education is a crucial element in contributing economic growth. Curriculum, assessment, teaching and learning are part and parcel in determining the success of school education system. Butler \& McMunn (2006) pointed out that the SBA curriculum empowers the educators and students to follow the teaching and learning process (instruction) based on the outlines given and enables assessment is for learning or assessment of learning. Assessment for learning rather than assessment of learning which according to Stiggins, (2005), focuses on year end assessment or summative assessment that emphasize on comparing students' achievement with others.

The current scenario with regards to assessment in Malaysia is that there is overemphasis on students getting 'A's. In other words, the Malaysian education system practices assessment of learning (ASLI-CPPS, PROHAM \& KITA-UKM, 2012). Hence, it influences the process of teaching and learning and educators tend to drill the students with the same patterns of questions. The government, realizing the negative impact of teaching merely 
to produce students who can churn as many A's has begun changing the assessment system. It is hoped that by changing the assessment system that places less emphasis on centralised, summative exam, will somewhat change the approach to teaching, hence the manner in which learning transpires. In short, the issue that the product of Malaysia education system is excellent in memorizing yet cannot put those knowledge into practice as suggested by Tan \& Samyudia (2009) should not take place.

The Ministry of Education since the past two years has engaged in aggressive effort to change the manner in which student learning is assessed. The assessment system known as School- Based Assessment (SBA) refers to the effort to move from reliance on centralised exam under the purview of the Malaysian Examination Board to a system where the teachers and schools are empowered to gauge student learning. Whilst it is not totally new, aspects of SBA have been mentioned via the former Minister of Education, Tan Sri Musa Mohamed in 2003 (Chan, Sidhu \& Md. Rizal, 2009).

\subsection{Research Framework of the Study}

Effective implementation of SBA warrants smooth interaction between and among many factors and parties. The following framework depicts variables involved in the implementation of SBA.

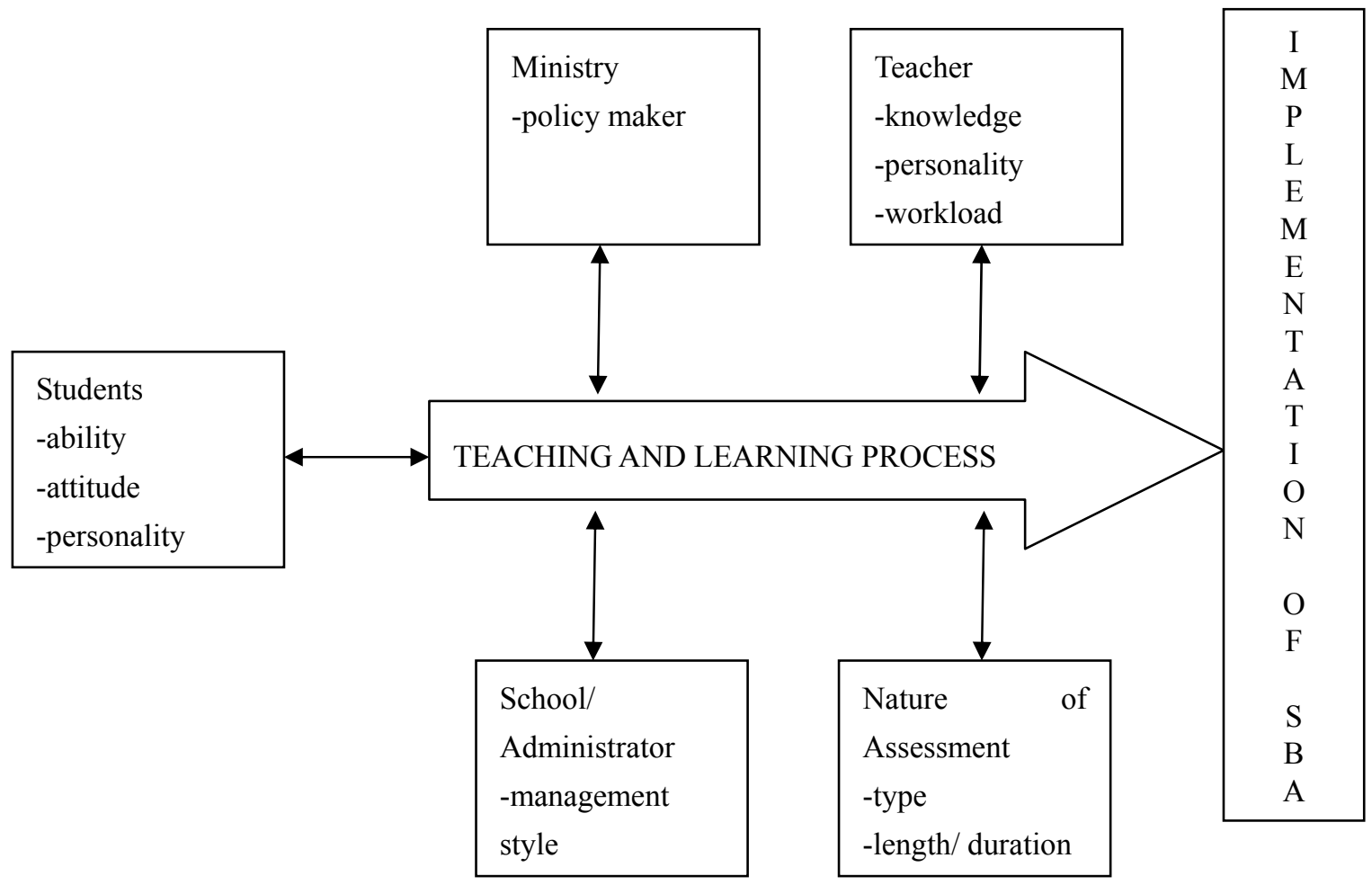

Figure 1. Implementation of SBAs in Malaysian schools

In reference to fig. 1, in principle, the ministry is responsible for planning, developing and executing the blueprint in the form of curriculum and assessment for teachers to implement. It is normally the case that the ministry's decision often impact on teachers' scope of responsibility and workload. Meanwhile, the school and school management serve as the caretaker that ensures policies implemented by the ministry. How flexible the school leaders when executing directives from top management also, to a certain extent, influence the smoothrunning of SBA implementation. Schools that are concerned over SBA implementation will definitely make certain that their teachers are knowledgeable in all aspects of SBA. The most critical implementer of SBA, however, would be the teachers. Teachers need to know how to plan and to have skills and knowledge to assess their students.

Jordan, Carlile \& Stack (2008) claim that education is a platform in developing holistic human capital which emphasizes on cognitive, affective and psychomotor domains. In order to measure whether the learning takes place effectively, assessment plays the main role (Walker \& Jonas, 2009). Ideally, assessments should promote rather than impede learning. Towards this end, School-based Assessment may have its merit as according to 
Chan, Sidhu \& Md Rizal (2009), School-based Assessment is based more on a concept of assessment for learning rather than a concept of assessment of learning.

Gijbel, Segers \& Struyf (2008) pointed out that assessment enables the instructors to find out if students have acquired a degree of holistic understanding of the overall lesson.

Johnston, J. Halocha \& Chater (2007) stressed that assessments which such focus on cognitive aspect only, and especially when testing is summative in nature, defeat the actual purpose of a test which should be a holistic and on-going, based on the actual teaching done. This was the practice in Malaysia before the introduction of School based Assessment (SBA). Johnston et al. (ibid.) also stated that such summative testing may result in the students feeling inferior and this may lead to loss of self-confidence.

Hedge (2010) asserted that SBA serves as a platform that may actually throw light on the progress of the teaching and learning process. Chan, Sidhu \& Md Rizal, (2009) pointed out that assessment is a lifelong process to improve and upgrade learners' ability. In contrast to the traditional summative assessments, researchers such as Stiggins, (2005) Johnston, Halocha \& Chater, (2007), pointed out that the formative assessment allow students' learning be guided according to their level of ability.

Formative assessment invites teachers to conduct on-going assessments and it empowers teachers' to shape the teaching and learning process without being constrained by the dictates of a centralised system or body such as a Ministry of Education, although such ministry is still responsible for defining the scope and content of the syllabus. This is the principle by which SBA is based on. It focuses on assessing the results of learning throughout the teaching and learning process.

Tan \& Samyudia, (2009) as well as Chan, Sidhu \& Md Rizal, (2009) pointed out that the SBA defends each of the students' right to receive educational input of equal quality and quantity. They argued that normally instructors perceive the goal of education as a mission to produce excellence. Schools are very proud when there is a high percentage of passes for government exams such as UPSR (exam upon finishing primary education) and PMR (An exam after three years of secondary education). In some extreme cases, very weak students were actually discouraged from taking government exams such as UPSR, (News Strait Times, 2010).

Fogarty (1998) \& Hedge (2010) state that by using SBA, students would have ample opportunities to become engaged in the learning process since among the characteristics of SBA include students being able to integrate their intelligence quotient, emotional quotient, spiritual quotient and physical strengths in their learning process, directly set the learning targets and relate the skills, knowledge and ideas with real life situations.

According to Mcleod \& Reynolds (2003), students have to be developed in three aspects namely, cognitive, social and physical domains. Hedge (2010) \& Dix (2010) stated that students' autonomy in learning is essential in developing the three main domains, ABS enable such autonomy. Sellan, Chong \& Tay, (2006) \& Tsheko, (2006) point out that individuals should acquire skills in solving problems by optimising their higher order thinking skills. Thus there is justification for the implementation of SBA as SBA stresses on the integration of intelligence with various aspects either in the social, economic, political and Information Communication Technology (ICT) arena.

\section{Problem Statement of the Study}

The purpose of the study is to determine secondary school teachers' knowledge regarding SBA for English Language teaching and learning. The study intended to find out specific issues faced by the teachers throughout the implementation of SBA. In addition, the study also seeks to examine factors contributing to problems in SBA implementation.

The change in assessment in school has led to some challenges on teachers' part. Khairiah (2008) discovered teachers encountered problems completing the assessment according to schedule and ensuring the authenticity of assessment; hence leading to the question of whether the teachers are capable and have sufficient knowledge to carry out SBA. Another study by Chan, Sidhu \& Md Rizal (2009) reported time constraint, increasing teacher work load, lack of knowledge, monitoring as well as supervision as obstacles to effective implementation of SBA. More recently, a study by Faizah (2011) echoed Chan et al. (2009) findings whereby the teachers are worried about several aspects of assessment including their abilities and roles to meet all the SBA requirements. In SBA, teachers would need to aid students individually to achieve their own band or standard without comparing with other students (Lucy, 2007).

\section{Methods and Materials}

This study employed both quantitative and qualitative methods which allows for quantitative data be 
corroborated through qualitative means, Fraenkel and Wallen (2009). Triangulation provides consistency of the results where it fortifies the validity and reliability of the outcomes (Cohen, Manion \& Morrison, 2007).

\subsection{Population and Sampling}

The population for this study are teachers teaching English Language in the district of Dungun Terengganu, specifically those who have been involved in the implementation of SBA since the beginning in 2012.

Out of this population, a sample of 60 teachers from 20 secondary schools was selected. Purposive sampling was done to ensure that the sample consists of teachers who Senior Assistants, Head of Departments, English Panel Heads and ordinary English teachers. Some stratification was done to ensure that there were a minimum of at least three representatives from each school. Out of the 60 sampled, 20 teachers were interviewed to obtain qualitative data that may back up the quantitative information.

\subsection{Questionnaire}

The instrument (questionnaire) used for this study was adapted from that used by established researchers such as Chan and Sidhu, (2012) and Faizah ( 2011). It consists of three sections. Section A deals with the Demographic Profile. While Section B deals with Knowledge of SBA and was adapted from Chan and Sidhu (2012). Section C, mainly adapted from Faizah's (2011), addressed the issues and implications of SBA to English Language teaching and learning. Section D, contained a set of interview questions. The questionnaire was only put to use after a pilot study for sections B and C were carried out.

\section{Analysis and Results}

The respondents involved in this study were secondary school teachers from the district of Dungun. All 60 respondents who came from 20 different schools are teaching English and have been involved in the implementation of SBA.

\subsection{Teachers' Knowledge Regarding School-Based Assessment (SBA)}

Teachers' knowledge regarding School Based Assessment (SBA) can be divided into three aspects, namely, knowledge in Planning the SBA, knowledge in Developing the SBA and knowledge in Analyzing the SBA.

\subsection{The Level of Teachers' Knowledge in Developing SBA}

The results indicated that the respondents have good knowledge in administering the classroom test (mean=3.55, $\mathrm{SD}=.815$ ) compared to other items. The item infers that the respondents know how students should be tested in class, which include the rules and regulations of testing. This finding was corroborated by the qualitative findings, and as a case in point, Tan (not real name) stated that:

I would rather say that every teacher has some experience and the as such implementing the SBA for administering classroom tests will not be so new or strange after all when it comes to administering the classroom tests.

\subsection{Knowledge in Developing the SBA}

Overall the teachers showed satisfactory knowledge when developing school-based assessments. Each of the 15 items for this section indicated a mean of more than 3 . Where 5 is the maximum mean and 1 the minimum mean, a mean score higher than the mid-point mean of 3 can be considered satisfactory for the purposes of this study. Nonetheless there is still room for improvement and hopefully with the passage of time, teachers can get more knowledge in developing SBA tests and might be able to return a mean score of 4 to 5 in future studies.

\subsection{The Level of Teachers' Knowledge in Analysing SBA Items}

Items relating to the above aspect taps into the teachers' knowledge on how scoring of various types of assessment which include multiple-choice and essay questions, as well as their know-how on varying analysis.

The lowest mean recorded for this section was for 'knowledge in calculating $z$-score.' (Mean=2.75, $\mathrm{SD}=.954$ ). This quantitative finding indicated that the respondents have limited knowledge in calculating the z-score. This finding was compatible with the qualitative findings. For example, Vashanti (not real name) who is a senior teacher had this to say:

My job as a teacher does not require me to calculate z-score. I learnt it during my first degree but I already forgot. So I do not have the skills to run it.

Overall, the teachers' knowledge of analyzing the SBA results was not really satisfactory. Out of the ten items in this section, five were found to have a mean less than a mid-point of three. Most of the remaining five items only managed a mean of slightly more than three. For the purposes of this study the teachers' knowledge of analyzing 
the SBA results is not really satisfactory and thus need to be further improved.

\subsection{Issues Faced by Teachers in Implementing SBA}

With reference to the issues faced by teachers in the implementation of SBA, Faizah's (2011) terms used in the framework of her study will be used.

\subsubsection{Indifference (to SBA)}

The lowest mean recorded for this section was 'I am concerned about $S B A$ ' (Mean=3.18, $\mathrm{SD}=.770$ ) and 'I am interested in learning about $S B A^{\prime}$ (Mean=3.17, $\mathrm{SD}=.615$ ). Those quantitative finding indicated that the respondents', on the whole, teachers are interested in wanting to know more about SBA. All three items in this section of the questionnaire indicated a value slightly above three which is the mid-point mean for each item. However the score is not very encouraging as the mean is only marginally above three. A mean score of near to 4 would have been more desirable. This finding concurred with the qualitative findings. Rani (not real name) who teaches English for form 1 mentioned that:

I learnt that the educational philosophy is to produce holistic individuals who possess good elements in the intellectual, spiritual, emotional and physical area. In my opinion the objectives of SBA is not much different from the previous philosophy as it also focuses on cognitive (intellectual), affective (emotion) and psychomotor (physical) items. I have prior knowledge regarding the main objectives of SBA and therefore I feel that I do not have to spend a lot of time getting to know SBA. I do have a certain limited interest in finding out more about SBA. I admit that I am not an expert yet in handling SBA and I confess that at this moment I am not looking into SBA very deeply as there are other duties to attend to.

\subsubsection{Informational-Personal}

Informational personal items focus on the teacher's awareness of what needs to be done when implementing SBA. Item also taps into personal awareness of how SBA changes their academic role and personal life (in terms of time, energy and commitments).

The results indicated that the respondents admit that their time, energy and commitments are require very much in demand in the implementation of SBA (mean $=3.57, \mathrm{SD}=.500$ ). This item scored the highest mean compared to other items. The respondents seem to know that the SBA requires a certain level of commitment from them. However in spite of knowing that SBA requires some commitment from them, their knowledge of matters pertaining to SBA such as how the marks are moderated, is not very encouraging. Of the four items in this section, two recorded a mean of less than three, while one was just marginally above three. Thus it shows that they have to work on their awareness of the importance of SBA and make earnest efforts to be better informed about SBA. The findings also corroborated with the qualitative findings.

\subsubsection{Management}

Management is the aspects of managing time to complete all tasks relating to SBA. The tasks include filling, key in data, planning for assessment, as well as managing students. The results revealed that the respondents agreed with the statement 'I do not know how to complete SBA tasks efficiently' (mean=3.10, $\mathrm{SD}=.871)$. It showed that the respondents have awareness of their weaknesses pertaining to SBA. However the scores from other items which are below three or just marginally above three shows that their actual knowledge about SBA is not as good as we might like it to be. The findings also agreed with the qualitative finding.

\subsubsection{Consequence-Collaboration}

The above construct focuses specifically how SBA impacts on personal activities and lives of others. Items include gauging own ability to work with others and to inform students about SBA.

It is clear that most of the respondents will let the students understand their role in SBA (mean=3.28, $\mathrm{SD}=.506$ ). However their degree of collaboration with other teachers handling SBA needs to be improved as most of the other means scores are either below three or just marginally above three. Three is the mid-point mean and a score well above three would be more reassuring to all concerned. The finding also corroborated with the qualitative findings.

\subsection{Factors Contributing to the Problems of SBA Implementation}

Based on the interviews as well as data informed from the questionnaire, the following have been identified as factors that contribute to difficulties in SBA implementation.

\subsubsection{Shortage of English Teachers}

One of the stumbling blocks that leads to inefficient implementation of SBA is due to the limited number of 
English teachers.

\subsubsection{Teacher Bias}

The evaluations of the assessments need to be done precisely. Reliability and validity take a vital role in measuring the effectiveness of the assessment. The measurement must be consistent so that there is an element of reliability. In other words, the results will not be doubted or questioned.

It is evident from the above that among the factors that contributed to problems in SBA implementation has to do in teachers' inability to separate personal from professional judgement. Teachers tend to be more lenient and over considerate instead of judging based students' actual ability

\subsubsection{Time Constraints}

Below are some of the responses from the teachers:

I am a form teacher who teaches English. I'm not only having to key in SBA marks. I have to key in sports data which is known as fitness test or 'Ujian Segak' in Malay. Sometimes the server is really slow and it can really eat up your time. The job of keying in never ends as there is always something new to key in. I feel burdened when I have to deal with so much clerical work like keying in and sorting students' data. I am also occupied with other things like being a mentor to my students. The schools or the education departments should make sure that the Information Communication Technology (ICT) facilities function well so that it would not take a teacher ages to finish the process of entering data.

Based on the interview responses, it is clear that amount of work; especially 'clerical one' that teachers need to carry out is overwhelming. Hence time to complete everything pose as one of the major factors that impede efficient implementation of SBA. This factor that somewhat impedes smooth implementation of SBA was also evident in the questionnaire.

\section{Discussion}

\subsection{Knowledge in Planning Lessons for SBA}

It is very heartening to note that the teachers knowledge of SBA focused lessons can be considered somewhat satisfactory although the introduction of SBA is still relatively new. It was introduced last year, in 2012, to secondary one students. At the time of writing this report, in May 2013, the SBA is only about 17 months old into its implementation in January 2012.

Problems in SBA implementation are not unique to Malaysia. Lo (2006) and Hammod and McCloskey (2008) reported similar difficulties pertaining to knowledge in planning SBA lesson in Hong Kong, USA, Finland, Canada, Australia, New Zealand, Korea and Japan. Naimah (2011) stressed on mentoring, monitoring and moderating as three main elements needed in ensuring that teachers get sufficient knowledge in planning lesson for SBA.

\subsection{Knowledge in Developing the SBA}

Overall, the teachers displayed somewhat satisfactory knowledge of constructing tests for SBAs.Educational administrators should allocate funds to engage testing experts to give courses and workshops to school teachers. The schools should send at least some teachers to all these courses. Those teachers who have attended some of these courses can be made key personnel. These key personnel can then give in-house training to other teachers in the school. It is hoped that over time teachers would become even better in constructing tests for SBA.

\subsection{Knowledge in Analyzing the SBA}

Teachers appeared satisfactorily knowledgeable in basic issues such as scoring MCQ questions, scoring essay questions as well as calculating means and standard deviations. However the findings show that the teachers have difficulty with the more complex aspects of test analysis such as calculating difficulty index, discrimination index, t-score and z-score. Since advanced test analysis is something that is quite new for the teachers, they need more courses to get familiar with such analysis.

\subsection{The Issues Faced by the Teachers in Implementing the School-Based Assessment}

\subsubsection{Indifference to SBA}

It is heartening to note that the teachers are not indifferent to SBA. The teachers' responses indicated that they are concerned about SBA. This is very much welcomed as most staff in an organisation tend to show some resistance when something new is introduced especially if the change disrupts their comfort zone. The school and the ministerial authorities should build on this positive attitude of the teachers and provide them with the 
necessary facilities, support and training.

\subsubsection{Informational-Personal (Personal Information Level of SBA)}

The respondents in this study appeared to know their roles when it comes to the assessment aspect. However teachers indicated difficulty in analyzing SBA scores. In particular, their response for "knowing how marks are moderated" which is relatively low suggest that there is a need to know how the process of moderation of marks needs to be carried out.

\subsubsection{Management of SBA}

Teachers indicated difficulty in proper management of SBA. Teachers mentioned that time constraint is a major problem as the SBA has many requirements including non-academic requirements entailing doing analysis and a lot of other paper work.

The ministry should really carry out a study to ascertain whether there is sufficient number of teachers prior to the implementation of a policy such SBAs. Alternatively, the educational planners might consider reliving the teachers of some of the administrative work.

\subsubsection{Consequence-Collaboration}

This refers to knowledge sharing and information dissemination in the implementation of SBA. Unfortunately, the teachers' level of collaboration is not very encouraging. This may not be due to lack of team spirit on the part of the teachers. The teachers may be too occupied

with their myriad duties and tasks such that they may be unable to hold beneficial discussions among themselves. To overcome this, the school authorities and the state education authorities should hold frequent workshops, seminars or even camps where teachers can meet and not only learn new stuff but also contribute to the knowledge of others through brainstorming in groups.

\subsection{Factors Contributing to the Problems of SBA Implementation}

\subsubsection{Shortage of English Teachers and Time Constraints}

Time constraints can be eased up somewhat if the shortage of English teachers is addressed. A qualitative investigation revealed that among the main problem faced by the teachers is time constraints due to many additional duties under SBAs. As suggested earlier, the ministry must take note of this and find solutions. Due to the scarcity of materials pertaining to SBA which is relatively new in Malaysia, teachers have to spend a long time developing these materials and attending workshops too.

\subsubsection{Lack of Impartiality in Assessments}

Teachers even raised the possibility of some teachers being kind to their students and as such exercise unreasonable leniency when grading to help their students gain entry into favoured residential schools or universities and colleges. 'There is also the possibility of extra judicial leniency to help their students win scholarships which may be limited in number.

In the beginning stages, the monitoring has to be regular and frequent until the teachers in the schools are used to the system and are able to come up with tests which are of the required difficulty level and also do not lack reliability and validity.

\section{Conclusion and Recommendations}

This study recommends that the SBAs should be adopted although in the beginning there are going to be lots of teething problems. Such teething problems are understandable as the introduction of any new program is always associated with the pangs of birth.

Noorazam pointed out that many parents are now educated and should be able to guide their children at home. SBAs enables parents to get involved in the education of the children, it makes parents and teachers partners in the education of their children. Noorazam also explained that the current learning system is too exam orientated leaving teachers with precious little time improve the students soft skills. As a result many students are deficient in soft skills such as communicative skills and creative thinking. Such a deficiency of soft skills makes it difficult for new graduates to find employment, Madihah (2009).

An important implication of this study is that the teachers are expected to be ready, objective, independent and professional when they execute SBA to replace Penilaian Menengah Rendah (PMR) exam in 2014, Noorazam (2011).

Future research should attempt to use a bigger population and a bigger sample size. The ministry should 
commission a nationwide study comprising a large stratified sample with representation from every state.

\section{References}

ASLI-CPPS, PROHAM, \& KITA-UKM. ( 2012). Education Reform and Process of Consultation. In Education Reform in Malaysia Report (pp. 1-35). Institute of ethnic Studies: Universiti Kebangsaan Malaysia.

Butler, S. M., \& McMunn, N. D. (2006). A Teachers's guide to classroom assessment: Understanding and using assessment to improve student learning. San Francisco: Jossey-Bass Teacher.

Chan, Y. F., Sidhu, G. K., \& Md. Yunus, M. R. (2009). School-Based Assessment Enhancing Knowledge and Best Practices. Selangor: Univision Press Sdn. Bhd.

Chuo, L. (2006). Breaking away from exam-oriented mentality through presentations in EST lessons. Jurnal Penyelidikan Tindakan IPBL tahun, 1, 54-72.

Cohen, L., Manion, L., \& Morrison, K. (2007). Research Methods Education. Madison Avanue, New York: Routledge.

Dix. (2010). The Essential Guide to Classroom Assessment. Great Britian, United Kingdom: Pearson Education Limited.

Fogarty, R. (1998). Problem Based Learning. United States of America: Skylight Training and Publishing, Inc.

Fraenkel, J., \& Wallen, N. (2009). Design and Evaluate Research in Education. Americas, New York: McGraw-Hill.

Gijbel, D., Segers, M., \& Struyf, E. (2008). Constructivist Learning Environments and the (im)possibility to Change Students' Perceptions of Assessment Demands and Approaches to Learning. Springer Science \& Business Media, 36(1), 431-443.

Hammond, D. L., \& McCloskey, L. (2008). Assessment for Learning Around the World: What Would It Mean to be Internationally Competitive. Phi Delta Kappan, 90(4), 263-272.

Hedge, T. (2010). Teaching and Learning in the Language Classroom. Oxford, New York: Oxford University Press.

Ishak, N. (2011). School-Based Assessment as Transformation in Educational Assessment. Paper presented at The $4^{\text {th }}$ International Conference on Measurement and Evaluation in Education. Retrieved from http://www.moe.gov.my

Johnston, J., Halocha, J., \& Chater, M. (2007). Developing Teaching Skills. New York, USA: Mc Graw Hill.

Jordan, A., Carlile, O., \& Stack, A. (2009). Approaches to Learning. New York, USA: Mc Graw Hill.

Kamil, K. H. M. (2008). The Implementation of the School-Based Oral English Test; A Case Study. Unpublished master dissertation, Mara University of Technology, Malaysia.

Lo, Y. C. (2006). Practice and Challenges of School-based Formative Assessment. Paper presented at the $32^{\text {nd }}$ Annual Conference of International Association for Educational Assessment: Assessment in an Era of Rapid Change: Innovations and Best Practices, Singapore. Retrieved from http://www.iaea.info/documents/paper_1162a1dcb9.pdf

Madihah, M. (2009). The Perception of Companies Pertaining to the English Adequacy of Newly Employed Graduates in Kemaman, Terengganu- A Survey Among GLC's and Private Sector, Unpublished Academic Study, Universiti Teknologi Mara.

Majid, F. A. (2011). School-based Assessment in Malaysian Schools: The Concerns of the English Teachers. Journal of Us-China Education Review, 8(10), 1-15.

McLeod. J. H., \& Reynolds. R. (2003). Planning For Learning. Victoria, Australia: Thomson Social Science Press.

News Strait Times. (2010). Parent Alleges Son Barred from Exam. New Straits Times, August 5.

Noorazam, N. (2011). Integrity will Create Confidence. New Straits Times, December 30.

Sellan, R. Chong, K., \& Tay, C. (Eds.). (2006). Assessment Shifts in the Singapore Education System. Paper presented at Singapore for Educational Assessment Conference. Retrieved from http://www.iaea2006.seab.gov.sg/conference

Stiggins, R. (2005). From Formative Assessment to Assessment FORLearning: A Path to Success in 
Standards-Based Schools, Phi DeltaKappan, 87(4), 324-328.

Tan. \& Samyudia. (2009). Learning Styles versus Teaching Styles: How to match them? Retrieved February 26, 2013, from http://www.curtin.edu.my/TLForum2009/images/TLOF09-17.pdf

Tsheko, G. N. (2006). A Teacher with a Vision and School Based Assessment. Paper presented at Singapore for Educational Assessment Conference. Retrieved from http://www.iaea.info/document

Walker, D. F., \& Soltis, J. F. (2009) Curriculum and Aims (5th ed.). New York: Teachers College Press.

\section{Copyrights}

Copyright for this article is retained by the author(s), with first publication rights granted to the journal.

This is an open-access article distributed under the terms and conditions of the Creative Commons Attribution license (http://creativecommons.org/licenses/by/3.0/). 